\title{
Reflection on Club Teaching Model of Public Physical Education in Yan'an University
}

\author{
Xiangle Meng \\ Physical Education College of Yan'an University, Yan'an, China \\ mz7006@126.com
}

Key words: Public physical education; Club teaching model; Yan'an university; Reflection

\begin{abstract}
Using the methods of text analysis, interview and logic analysis, it made a reflection on the club teaching model of public physical education in Yan'an University. The results show that adopting club teaching model in public physical education was in line with the trend of teaching reform and development, and considered to be a valuable thing. However, there were many problems in teaching methods and means, assessment system and methods, faculty and teaching facilities etc. What' more, because of problems mentioned above, the teaching effects of the club teaching model were not obvious, even be weakened to some extent. It is concluded that the club teaching model of public physical education in Yan'an University is still in an experimental stage, and has not yet had the essential characteristics of the club teaching model, not to say the timeliness and effectiveness. Therefore, there is still a long way to go.
\end{abstract}

\section{Introduction}

The sports club, refers to certain freedom and independence, democracy and solidarity with the characteristic of sports as the core of the team, is a new teaching model in classroom teaching organic combination of college sports teaching and extracurricular sports exercise, the three, the teaching model is more conducive to the lifelong sports ability of students at different levels of development [1]. With the national college sports curriculum reform after another, Yan'an University is also brewing in the teaching reform of public physical education. From 2015, by visiting and investigating the teaching reform colleges and universities prescribed by the Ministry of Education, Yan'an University has determined to implement the club teaching model, and finally launched the club teaching reform model in the second half of 2015.

So far, a year has passed, however, teachers and students did not feel the new changes brought about by the club teaching model, and did not feel the club teaching should be the characteristics of the model and better learning results. After the reflection, the club teaching model of Public Physical Education in Yan'an University has not solved a series of problems that correspond to the teaching characteristics of the club. These problems are analyzed, and some countermeasures are put forward.

\section{The existing problems}

\section{Lack of novel teaching methods.}

Since ancient times, our country has followed the traditional education model of "speaking listening", and the physical education is no exception. Similar to indoor sports teaching and other subjects of education, students' interest in learning effects of boring classroom atmosphere and inflexible teaching environment; outdoor sports teaching is the traditional "preparing activity teaching activities - free activity" model, which is called three stage type teaching model. In the process of teaching, students do what teachers ask them to do, and lack of interaction between them. The model is too stylized to reflect the physical education curriculum objectives, causing students to ignore the importance of physical education curriculum [2]. In the content, some college PE teachers in physical education, physical fitness, only concentrating on the key communication 
technology as the core of health education, ignore the psychological development of students and the scientific maintenance of the body, the lack of correct guidance of lifelong sports consciousness of students, fall behind in the development of the times [3]. Students not only reject the teaching of physical education, but also not be fair and unity and other sports spirit of infection, easy to develop bad habits, it is difficult to create a good sense of physical education.

\section{The evaluation method is single, and the evaluation system is not perfect.}

The current evaluation model of club teaching still follows the traditional sports evaluation model, which is based on the skills assessment. At the same time, the inspection method is too simple, simple, cannot fully reflect the students' performance, that is, the lack of process evaluation. For example, in poor physical school some students do not love sports, after a year of college physical education, although the sports ability and sports technology compared to other students is still not mature, but compared to itself is a great breakthrough, if the score evaluation according to the traditional way, it is difficult to see its progress also, to dispel the enthusiasm of the students of physical education curriculum for physical exercise, counterproductive, causing some students to dislike the study of the physical education curriculum and cheat on the physical examination and physical fitness test. Obviously, this is not only disrespectful for the teaching of physical education, but also not responsible for their selves' physical and mental health. In view of this phenomenon, Yan'an University should start a deep thinking, what is the cause of the students' weariness and slack phenomenon. At the same time, should avoid the secondary impact of students' bad physical education learning behavior, and actively improve the content system and evaluation methods, means, etc.

\section{Teacher team structures are irrational.}

At present, the emerging leisure sports activities are constantly emerging, synchronized with the traditional sports programs, and so that the opportunities for students to participating variety of sports significantly increase. In many universities, the traditional sports, such as basketball, football, volleyball, track and field sports, require few on sports facilities, are easy to carry out, and the teaching content are relatively simple, professional teachers are abundant, so the project development is good. While, sports like swimming, tennis, sports dance, aerobics and other fashion sports are welcomed by students, but many universities don't do well, even some institutions do not offer these items, the reason is not only lie in the lack of facilities, but also the lack of professional teachers.

In addition, due to the impact of traditional sports, being regarded as "subject", the prejudice is deep, the sports teaching of less investment, the treatment of teachers compared to teachers of other subjects low enthusiasm, in a certain extent on the physical education teachers work [4], innovation consciousness is not strong, and the physical education teachers in many non professional personnel are uneven in quality, physical education teaching, but also reduces the overall level of research ability of PE teachers, college physical education makes teachers difficult.

\section{Teaching facilities and faculty are weak.}

The general higher college and university sports stadium is not only an important part of the whole social sports facilities, but also plays an important role in enhancing the consciousness of the national physical fitness and carrying out the national fitness campaign [5]. In 2004, the Ministry of Education issued a "school sports facilities, equipment, equipment, equipment", clearly stipulates that the university should have the sports facilities, equipment and site requirements. However, due to the narrow part of college education "re-examination, light quality" concept, the funds to put into the construction of sports facilities in many colleges and universities, and even reach the "basic" staffing levels, has seriously affected the sports teaching effect. For example, For example, due to the lack of tennis teaching field, use the football field to carry out tennis teaching, which not only make the teaching effect adversely affected, but also easily lead to accidents and reduce the enthusiasm of teaching, students' physical education learning. 


\section{Analysis of the Countermeasures}

\section{Set teaching goal system with the characteristic of the club teaching model.}

The university is conveying excellent builders of socialism as a national base, in addition to its delivery of talent with excellent morality, solid professional knowledge and strong practical ability, the construction should also have good health to bear the future of personal and national career. The famous educator Mr. Tao Xingzhi had advocated "sports to self-reliance", we must first develop the students "strong physique", students are required to establish a "health fortress", and asserts that "healthy body is everything" [6]. Therefore, the education of physical education is very important, and it is worth to be educated and educated. College physical education should take the students as the method to attract interest, cultivate a lifelong sports consciousness as the core, that the successor of health for the purpose of cultivating qualified countries deepen the reform of university physical education problems and countermeasures. Physical education curriculum cannot achieve this standard, so through the sports curriculum reform, to mobilize the enthusiasm of the students to exercise, so as to cultivate students' voluntary lifelong physical habits, let the student lifelong benefit from the new teaching model.

\section{Use reasonable teaching methods and means according to the club teaching model.}

In a high autonomy of study today, the traditional teaching has not complied with the requirements of the times. College students who was born after 1990s and 1995s have distinct personality, purist novelty things, so the dull pedantry "speak - listen" teaching model will stifle students learning enthusiasm, and is also not conducive to their own creativity and autonomy. The sports new curriculum advocate humanism situation, physical education teachers in Colleges and universities should be from the "management and control" change to the current "organization, promote the change from the past"; "the teacher's dignity" to the current "parents" and "friends" [7]. We should pay attention to the balance between teaching and student activities, not only to the attention of sports activities and action essentials to tell clearly, but also to ensure that students' innovative attempt and active activities. It is not only to cultivate students' interest in physical education, but also to use innovative teaching content and teaching methods, to guide students to physical education, and to promote the healthy development of students' mental health [8]. Still we can use some more of the independent teaching model, for example: novel had the sport experience for students to share their experience in sports, teachers can explain the phenomenon from the analysis; at the higher the enthusiasm of students in physical education, teachers can interact with, such as table tennis, tennis and so on, teachers can take the initiative to feed the ball and through the actual interaction, correct students' irregular movements; independent elective courses in advance to a large, let the students choose to study courses based on personal interests and so on. The improvement of teaching means is mainly to cater to the needs of the educated, and at the same time to meet their needs, complete sports awareness training.

\section{Perfect evaluation system, scientific evaluation of students' performance.}

Our country has an ancient history of the examination, and "a test for life" has been the formation of the historical tradition of our nation. In today's society, the examination is still relatively fair means to show the ability of candidates, but the bias is also more prominent. Physical education in colleges and universities is an open teaching activity, which can reflect the students' classroom learning effect, but it is not completely open. The current evaluation system, the method of multiple references, longitudinal should be improved. The "taking exam frequently" is to play a decisive role on the bias, the results are not satisfied the students can apply for re examination, take the exam two times better than the original is; longitudinal, poor physical fitness, sports performance is not good for students, teachers in the evaluation should give for their own progress, discretionary bonus; often refers to the experience in the whole teaching process, repeatedly examine for the class, the teacher can through conversation, for training and evaluation to students, and usually lectures attitude as assessment indicators into the performance category, in order to better show the 
enthusiasm and progress of students' physical education learning.

\section{Summary}

The club teaching model of public physical education in Yan'an University has just recently, so there are some obvious problems, but the direction of exploration is correct. Therefore, on the basis of maintaining the club teaching model, there are some things need to be changed, such as revising club teaching objectives, optimizing teaching contents, teaching methods and teaching means, formulating scientific performance evaluation system, improving the level of teachers, enriching facilities. Only by this way, can the club teaching model live up to its name.

\section{References}

[1] Ban Kai. On the problems and Countermeasures of the development of sports clubs in Colleges and Universities[J]. Contemporary Sports Science and Technology, 2014, 4(25):77-78.

[2] Chen Xiugui. Path Innovation of College Physical Education in the new era [J]. China Education Innovation Herald, 2012 (11):201- 202.

[3] Luo Xichang, Yang Hongwei. On Mistaken Ideas and Tactics in Higher Physical Education in China [J]. Journal of Shandong Sports Institute, 2008, 24(5):83-85.

[4] Jie Mengning. Construction of New Teacher-Student Relationship of Sunshine Sports and Physical Education in Colleges and universities [J]. Chinese adult education, 2010(10): 154-155.

[5] Dong Chengwei, Yin Jiahong. Study on the Operation, Management and the Economic Returns of the College Stadiums in Kunming [J]. Journal of Zhaotong University, 2008, 30(5): 62-64.

[6] Mou Yan. Study on the Pragmatism Thought of Sports in the Period of Republic of China [D]. Suzhou: Suzhou University, 2005: 27-28.

[7] Shao Xishan, Liu Yao. Occupation Burnout of PE Teachers' Teaching Career Cycle [J]. Journal of Physical Education, 2008, 15 (8):57-60.

[8] Guo Lu. Characteristics of Athlete Coping Styles and Self-consciousness Relation - A Typical Correlation Study [J]. Journal of Beijing Sport University, 2013, 36(2):84-87. 